\title{
SOBRE O USO DE ALGEMAS (RESTRIÇÕES A DIREITOS FUNDAMENTAIS E PROPORCIONALIDADE)
}

\author{
Daniel Addor Silva*
}

Alvacir Alfredo Nicz*

\section{RESUMO}

O presente trabalho traça breve análise acerca dos direitos fundamentais e sua possibilidade de restrição. Em seguida, aborda-se a proporcionalidade e o uso de algemas, com seu tratamento legal e judicial. Por fim, analisa-se o uso de algemas à luz da proporcionalidade.

Palavras-chave: Proporcionalidade. Restrições a direitos fundamentais. Uso de algemas.

\section{INTRODUÇÃO}

Na manhã de 08/07/2008, a mídia surpreendeu os espectadores - assim como, obviamente, os próprios investigados -, divulgando, ao vivo, uma operação deflagrada pela Polícia Federal, denominada Operação Satiagraha ${ }^{1}$, com o cumprimento de mandados de prisão temporária e busca e apreensão. $\mathrm{Na}$ oportunidade, foram presos, dentre outros, um banqueiro investidor, um especulador financeiro e um ex-prefeito de São Paulo. Quanto a este, causaram surpresa as imagens da sua prisão, na porta de seu apartamento, com o uso de algemas.

Sem fazer qualquer comentário específico quanto à necessidade e à legalidade das prisões, deve-se esclarecer que, no presente caso (assim como na quase totalidade das operações recentes), tem-se feito uso da prisão temporária, prevista nas hipóteses e nos crimes do art. 1ํㅡㄹ da Lei $n^{\circ} 7.960 / 89^{2}$, medida autorizada judicialmente (de maneira fundamentada, como sói acontecer) diante de necessidade demonstrada.

A par de toda a questão da exploração midiática das prisões - que comportaria um estudo específico ${ }^{3}-$, salienta-se a crítica, cada vez mais recorrente, acerca do uso de algemas. Qualquer análise sobre o tema, ainda que superficial, não prescinde da ótica constitucional, que, aliás, deveria orientar a averiguação acerca de qualquer assunto ${ }^{4}$. Nesse ponto, a análise pela via da proporcionalidade se mostra uma excelente ferramenta de trabalho.

Não se pretende, como cediço, esgotar o tema, mesmo porque a proporcionalidade possui não somente vasto material publicado, como também há possibilidade de produção de mais obras. Objetiva-se, portanto, trazer 0 debate sobre o tema - já instaurado na imprensa, na Política e submetido à 
opinião pública - para a área jurídica.

Parte-se, assim, de breve análise dos direitos fundamentais e sua possibilidade de restrição. Em seguida, aborda-se a proporcionalidade e o uso de algemas, com seu tratamento legal e judicial. Por fim, analisa-se o uso de algemas à luz da proporcionalidade.

\section{DIREITOS FUNDAMENTAIS E SUA RESTRIÇÃO}

Promulgada a Constituição Federal, em 1988, já há vinte anos, operouse verdadeira revolução no ordenamento jurídico. Primeiramente por consolidar a transição democrática após a ditadura militar. Além disso, é certo que nossa Constituição não diz respeito tão-somente à organização do Estado, mas ousou adotar postura principiológica e garantista, como se depreende dos títulos I e II, notadamente o art. 50, que prevê quase exaustivamente direitos e garantias, além daqueles espraiados pelo texto constitucional.

A constitucionalização de determinados institutos antes relegados à legislação ordinária acarretou uma releitura da aplicação destes dispositivos. Por tal razão, foi denotada a real importância da teoria da recepção, com o expurgo de todas as normas (ou interpretações) contrárias à nova ordem constitucional.

Por certo, a Constituição prevê expressamente extenso rol de direitos e garantias fundamentais, com aplicação imediata, conforme preceitua o art. 5o, § $1^{\circ}$. De acordo com o $\S 2^{\circ}$ do art. 5을 nossa Carta Magna ainda reconhece a existência de direitos implícitos, "decorrentes do regime e dos princípios por ela adotados, ou dos tratados internacionais em que a República Federativa do Brasil seja parte". No entanto, não se pode assumir, precipitadamente, que tais direitos sejam absolutos ou irrestritos.

Canotilho aborda a questão da metódica da restrição de direitos, liberdades e garantias. Inicialmente, salienta ser necessário analisar a norma constitucional e verificar seu âmbito de proteção, ou seja, "quais os bens jurídicos protegidos e a extensão dessa protecção"s. Autores como Bodo Pieroth, Bernhard Schlink e Konrad Hesse consideram o âmbito de proteção "aquela fração da vida protegida por uma garantia fundamental"6. Identifica-se não somente o que é efetivamente protegido (objeto da proteção), assim também contra que agressão ou restrição é protegido ${ }^{7}$. Deve-se verificar se os bens jurídicos "sofrem de qualquer restrição imediatamente estabelecida pela própria constituição - restrição constitucional expressa - ou se a constituição autoriza a lei a restringir esse âmbito de protecção - reserva de lei restritiva"§.

De acordo com Canotilho, após a definição do âmbito de proteção, o segundo passo é "averiguar o tipo, natureza e finalidades da medida legal restritiva" .

As restrições constitucionais imediatas são aquelas previstas pelas próprias normas constitucionais, v.g., o art. 5ํ, XVI, da Constituição Federal, 
prevê como limite expresso do direito de reunião o seu caráter pacífico e desarmado; 0 art. 5o, XVII, da Constituição Federal, impõe como limite expresso do direito de associação a vedação ao seu caráter paramilitar. Tais normas são não somente normas de garantia de direitos, por garantirem, constituírem ou reconhecerem um âmbito de proteção ao direito, mas também normas limitativas de direitos, por estabelecerem imediatamente limites ao âmbito de proteção.

Pode haver restrições estabelecidas por lei quando a própria norma garantidora a admite expressamente (reserva da lei restritiva), v.g., segundo 0 art. 5․, XII, da Constituição Federal, a lei pode estabelecer forma e hipóteses de violação do sigilo das comunicações telefônicas, como de fato o fez (Lei no 9.296/96). Neste caso, a norma é simultaneamente norma de garantia e norma de autorização de restrições, por autorizar o legislador a estabelecer limites ao âmbito de proteção.

Mendes et al $^{10}$ dividem a reserva legal em simples e qualificada, conforme a exigência que o constituinte faça ao conteúdo ou à finalidade da lei restritiva. $l e i^{11}$.

$\mathrm{Na}$ reserva legal simples, exige-se apenas que a restrição seja feita por

$\mathrm{Na}$ reserva legal qualificada, a Constituição estabelece condições especiais, fins a serem perseguidos ou meios a serem utilizados ${ }^{12}$.

Há direitos que preexistem a qualquer disciplina jurídica, tais como vida e liberdade de locomoção. Entretanto, há outros direitos, como a propriedade, o casamento e o direito de herança, que dependem do legislador para definir 0 seu próprio conteúdo, ou seja, têm o âmbito de proteção instituído direta e expressamente pelo próprio ordenamento jurídico. Nesses casos, não se fala em restrição, mas em regulação ou conformação $o^{13}$ e as leis referentes a tais direitos não serão restritivas, mas normas de concretização ou de conformação. O legislador tem, ao mesmo tempo, um dever de preservar a garantia e um "dever de legislar, isto é, o dever de conferir conteúdo e efetividade aos direitos constitucionais com âmbito de proteção estritamente normativo"14. interna $^{15}$.

$\mathrm{Na}$ relação entre direito e restrição, existem duas teorias: externa e

Para a teoria externa, existe um direito ilimitado que, com a imposição de restrições, passa a ser limitado. Entre direito e restrição não existe uma relação necessária, que se justifica para compatibilizar direitos individuais e bens coletivos. Associa-se a uma concepção individualista da sociedade e do Estado e à noção de que os direitos individuais definem apenas posições prima facie (princípios).

Por outro lado, a teoria interna considera a idéia de direito individual com determinado conteúdo, substituindo restrição por limite. Vincula-se a uma necessária integração do indivíduo na comunidade e à noção de que os direitos 
individuais consagram posições definitivas (regras).

No caso dos direitos fundamentais sem expressa previsão de reserva legal, o legislador não pode ultrapassar, em princípio, os limites definidos no âmbito de proteção. Essa sorte de direitos nem sempre goza de efetiva proteção, pois pode sofrer restrição diante de eventual colisão. Ainda, segundo Juan Carlos Gavara de Cara, "o legislador pode justificar sua intervenção com fundamento nos direitos de terceiros ou em outros princípios de hierarquia constitucional"16. Em nossa Constituição Federal, pode-se recorrer à cláusula aberta da reserva legal subsidiária do art. 5ำ II, devendo-se, porém, para evitar abusos, fundamentar a limitação em outra norma constitucional.

Existem ainda restrições não expressamente autorizadas pela Constituição, reconhecida por alguns doutrinadores como limites imanentes ${ }^{17}$, dentre as quais se insere a proporcionalidade.

\section{PROPORCIONALIDADE}

Inicialmente, deve-se recordar a advertência do publicista francês Xavier Philippe de que "há princípios mais fáceis de compreender do que definir"18, servindo certamente como exemplo a proporcionalidade. Todavia, na tentativa de definir, com base em Pierre Muller, Bonavides traz o princípio da proporcionalidade em sentido amplo como "a regra fundamental a que devem obedecer tanto os que exercem quanto os que padecem o poder"19. Em dimensão mais restrita, "o princípio se caracteriza pelo fato de presumir a existência de relação adequada entre um ou vários fins determinados e os meios com que são levados a cabo"20.

Canotilho trabalha a proporcionalidade como princípio ${ }^{21}$ da proibição do excesso - erigido pela Constituição Portuguesa à condição de princípio constitucional, ao contrário de nossa Constituição Federal -, considerando-o um subprincípio concretizador do princípio do Estado de Direito ${ }^{22}$. $^{23}$

Não se pretende no presente trabalho, em razão de sua brevidade, tratar das origens históricas do princípio. Entretanto, é interessante salientar que a proporcionalidade remonta ao século XVIII, como máxima suprapositiva, para limitação do Poder Executivo, como "medida para as restrições administrativas da liberdade individual"24 25 .

Apesar de não haver consenso na doutrina ${ }^{26}$, pode-se salientar a existência de três corolários, elementos, conteúdos parciais ou subprincípios da proporcionalidade: a) adequação (de meios), pertinência, aptidão, idoneidade ou conformidade; b) necessidade, exigibilidade ou menor ingerência possível; c) proporcionalidade em sentido estrito (ou restrito).

A idoneidade pressupõe uma adequação entre fim pretendido e meio escolhido para tanto. Analisa-se a possibilidade de se atingir o objetivo perseguido. 
A necessidade exige a verificação, para a obtenção do fim, da utilização do meio menos oneroso para 0 cidadão ${ }^{27}$. Deve-se analisar, concomitantemente, "a menor restrição ao direito e a maior eficácia de resultado" ${ }^{28}$. Então, "a medida não há de exceder os limites indispensáveis à conservação do fim legítimo que se almeja, ou uma medida para ser admissível deve ser necessária"29.

A proporcionalidade em sentido estrito é a "justa medida", devendo-se perquirir "se o resultado obtido com a intervenção é proporcional à <<carga coactiva >> da mesma" 3031 .

\section{USO DE ALGEMAS}

Traçadas as linhas gerais da proporcionalidade, cumpre tecer breves comentários sobre o tratamento do uso de algemas na legislação (existente e vindoura) e nas decisões judiciais ${ }^{32}$.

O Código de Processo Penal, em seu art. 284, ao tratar da prisão, estabelece que "não será permitido o emprego de força, salvo a indispensável no caso de resistência ou de tentativa de fuga do preso".

Recentemente, a Lei oㅜ 11.689/2008 alterou o art. 474, do Código de Processo Penal, incluindo também $\S 3^{\circ}$, cujo teor veda o "uso de algemas no acusado durante o período em que permanecer no plenário do júri, salvo se absolutamente necessário à ordem dos trabalhos, à segurança das testemunhas ou à garantia da integridade física dos presentes".

Especificamente sobre o emprego de algemas, o Código de Processo Penal Militar, Decreto-Lei no 1.002/69, dispõe, em seu art. 234, § 1ํㅜ que "deve ser evitado, desde que não haja perigo de fuga ou de agressão da parte do prêso", impossibilitando seu uso em determinada categoria sujeita a prisão especial (art. 242), v.g. "diplomados por faculdade ou instituto superior de ensino nacional" (art. 242, h). Exsurge, assim, de plano, a natureza nitidamente desigual da norma.

Por sua vez, a Lei de Execução Penal, Lei no 7.210/84, relega a disciplina do uso de algemas a decreto federal (art. 199).

Diante da inércia do Executivo em exercer seu poder regulamentar, adveio iniciativa do legislador. O Projeto de Lei no 2.753/2000, de autoria do Deputado Alberto Fraga (PMDB-DF), congrega os demais projetos no mesmo sentido e em breve será submetido a plenário ${ }^{33}$.

Se aprovado o projeto, somente será possível algemar o conduzido quando houver resistência à prisão, fuga ou sua tentativa e risco à integridade física própria ou alheia. Ainda, quando o número de presos excederem o número de agentes condutores ou o deslocamento resultar de comparecimento em Juízo. Percebe-se que esta última hipótese confronta-se com a tendência jurisprudencial dos Tribunais superiores, conforme adiante se verá. Além disso, o uso de algemas ficará a cargo da autoridade policial que chefiar a operação 
ou, em uma interpretação mais ampla, da autoridade judicial ${ }^{34}$ que determinar a medida constritiva, dado que pode ser "imediatamente responsável pela ação policial" não somente quem detém o domínio do curso dos fatos como também aquele que a autorizou.

No plano judicial, duas decisões do Superior Tribunal de Justiça merecem destaque. A primeira delas diz respeito à fixação de parâmetros para o uso de algemas, em caso envolvendo juiz federal preso durante a chamada "Operação Anaconda"35 (HC 35540/SP, 5a Turma, Rel. Min. José Arnaldo da Fonseca, julg. 05.08.2004, DJ 06.09.2004, p. 285) ${ }^{36}$. Por sua vez, a segunda indaga se é possível atribuir responsabilidade ao Estado em razão do dano decorrente de seu emprego supostamente indevido (REsp 571.924/PR, 2 ${ }^{a}$ Turma, Rel. Min. Castro Meira, julg. 24.10.2006, DJ 10.11.2006, p. 255) ${ }^{37}$.

No Supremo Tribunal Federal, paradigmática se afigura a apreciação da questão (HC 89429/RO, 1a Turma, Rel. Min. Cármen Lúcia, julg. 22/08/2006, DJ 02/02/2007, p. 920) $)^{38}$ quando, por ocasião da chamada "Operação Dominó"39, um conselheiro do Tribunal de Contas do Estado de Rondônia pleiteou o direito de não ser algemado nem ter sua imagem capturada pela imprensa. A decisão estabeleceu os parâmetros do que entende serem as "finalidades" do uso de algemas, quais seriam: impedir, prevenir ou dificultar a fuga ou reação indevida do preso, desde que haja fundada suspeita ou justificado receio de que tanto venha a ocorrer, e para evitar agressão do preso contra os próprios policiais, contra terceiros ou contra si mesmo ${ }^{40}$. Ademais, reconhece expressamente que "o emprego dessa medida tem como balizamento jurídico necessário os princípios da proporcionalidade e da razoabilidade" ${ }^{\prime 1}$.

Recentemente, em sessão do dia 07/08/2008, na apreciação do HC 91952/SP, o pleno da Suprema Corte, por unanimidade, acompanhou voto do Rel. Min. Marco Aurélio e deferiu ordem para anular julgamento do Tribunal de Júri em que o paciente permaneceu algemado durante todo o tempo. Por certo se tratava de situação peculiar e adequada aos novos ditames processuais penais. Mas, na oportunidade, o eminente Relator recordou que se viu "nos veículos de comunicação, algemadas pessoas sem o menor traço agressivo, até mesmo outrora detentoras de cargos da maior importância na República, em verdadeira imposição de castigo humilhante, vexaminoso"42.

Dessarte, por sugestão do Relator, na seqüência das mencionadas decisões e apenas mais dois precedentes ${ }^{43}$, em 13/08/2008, foi aprovada a súmula vinculante $\mathrm{n}^{\circ}{ }^{1} 1^{44}$, com base essencialmente em redação do Ministro Cezar Peluso, no seguinte teor:

Só é lícito o uso de algemas em casos de resistência e de fundado receio de fuga ou de perigo à integridade física própria ou alheia, por parte do preso ou de terceiros, justificada a excepcionalidade por escrito, sob pena de responsabilidade disciplinar, civil e penal do agente ou da autoridade e de nulidade da prisão ou do ato processual a que se refere, sem prejuízo da responsabilidade civil do Estado. 
Nesses moldes, por ora, a questão se encontra assentada, obrigando o Estado à devida aplicação da súmula. Entretanto, felizmente, a eficácia vinculante da súmula não afasta a possibilidade de discussão acadêmica sobre 0 assunto.

\section{INDAGAÇÕES SOBRE O CASO}

A princípio, a liberdade é inviolável, nos termos do art. 5ํㅜ caput, da Constituição Federal. Ademais, "é livre a locomoção no território nacional em tempo de paz, podendo qualquer pessoa, nos termos da lei, nele entrar, permanecer ou dele sair com seus bens" (art. 5ำ XV, CF) ${ }^{45}$.

Assegura-se, ainda, a possibilidade de prisão somente "em flagrante delito ou por ordem escrita e fundamentada de autoridade judiciária competente" (art. 5ํ, LXI, CF). Trata-se de restrição constitucional direta ou imediata, pois estabelecida pelo próprio texto constitucional.

Em que moldes, então, pode ser decretada a prisão? Por certo, não pode ser ilegal ou oriunda de abuso de poder, caso contrário será passível de Habeas Corpus, previsto pelo art. 5ํ․ LXI, da Constituição Federal. Outra baliza da prisão é a vedação a tratamento desumano ou degradante, determinada pelo art. 5ำ III, da Constituição Federal.

Delineado o âmbito de proteção, a questão que se impõe é se e quando o uso de algemas configura ilegalidade, abuso de poder ou tratamento desumano e degradante.

Para tanto, imperioso indagar o que representam as algemas.

Nesse ponto, a primeira decisão citada do Supremo Tribunal Federal traz a definição e traça importante histórico, à qual se remete em razão da brevidade.

Desnecessário, outrossim, demonstrar que o uso regular de algemas visa evitar a fuga do preso e assegurar a sua segurança e dos demais, como de fato reconheceu o voto do Ministro José Arnaldo da Fonseca proferido no citado acórdão do Superior Tribunal de Justiça. Deve-se destacar as razões do Parquet, adotadas pelo julgador, segundo o qual "o uso de algemas tem nítido sentido constrangedor, mas, pode haver fim lícito ou ilícito". Assim, será devido o uso de algemas quando elas se dirigirem aos fins que originalmente se propõem.

Olvidam-se os críticos do uso de algemas que a prisão, por si só, representa gravame à liberdade de locomoção. Se o indivíduo terá cerceada integralmente sua liberdade, em que medida a limitação dos movimentos dos braços pode lhe ser pior? Em princípio, a condução do preso sem algemas não Ihe devolve a condição de homem plenamente livre. Da mesma forma, pode-se concluir que levar o preso algemado não lhe agrega nenhuma outra condição, tampouco confere caráter desumano e degradante ao tratamento além do inerente à própria privação de liberdade. 
De outra banda, as algemas podem representar um símbolo. Nesse sentido, percebe-se que a insurgência, via de regra, não diz respeito ao uso de algemas em si. A indignação dos algemados e daqueles que thes dão voz parece sempre se dirigir à exibição pública, com as conseqüências prejudiciais que lhes são inerentes, mormente a captação de imagens, o pré-julgamento público decorrente e os efeitos danosos à moral dos atingidos pela medida.

Nessa esteira, a reportada decisão do Supremo Tribunal Federal em Habeas Corpus destaca que as algemas simbolizam a ação policial e a submissão do preso, "e é com essa figuração que pode se tornar uma fonte de abusos e de ação espetaculosa, que promove a prisão como forma de humilhação do preso e não de garantia da segurança das providências adotadas". Em tal sentido é que a Relatora considera, inclusive, abuso de autoridade 0 uso indevido de algemas, nos termos do art. $4^{\circ}$, b, da Lei $\mathrm{n}^{\circ}$ $4.898 / 65^{46}$. No mais, os votos dos Ministros são no sentido de repudiar a utilização do preso algemado como troféu da atuação policial.

Da mesma forma, durante os debates para aprovação da súmula vinculante, o Presidente do Supremo Tribunal Federal não hesitou em salientar:

\begin{abstract}
$\mathrm{Na}$ verdade, quando estamos a falar hoje desta questão da algema, na prática brasileira, estamos a falar da aposição da algema para os fins de exposição pública, que foi objeto inclusive de considerações específicas no voto do Ministro Marco Aurélio. De modo que é preciso que estejamos atentos. Certamente temos encontro marcado também com esse tema. A Corte jamais validou esse tipo de prática, esse tipo de exposição que é uma forma de atentado também à dignidade da pessoa humana. A exposição de presos viola a idéia de presunção de inocência, viola a idéia de dignidade da pessoa humana, mas vamos ter oportunidade, certamente, de falar sobre isto.

Neste caso específico, a aplicação da algema já é feita com o objetivo de violar claramente esses princípios. Em geral, já tive a oportunidade de dizer, algemar significa expor alguém na televisão nesta condição, ou prender significa hoje algemar e colocar alguém na televisão. De modo que é esta a questão que precisa ser de fato enfatizada, e ao Ministério Público incumbe a missão também de zelar pelos direitos humanos. É fundamental que ele coarcte essas ações, inclusive propondo os inquéritos devidos, as ações penais de responsabilidade, se for o caso. ${ }^{47}$
\end{abstract}

Parece, assim, que o excesso não está em se algemar, mas em se exibir a pessoa algemada. Não se pode, porém, olvidar da existência de periódicos e programas televisivos especializados na divulgação de fatos policiais. Diariamente, tem-se a exposição de indivíduos, suspeitos da prática de crimes, por assim dizer, "tradicionais", v.g., furto, lesões corporais etc. Entretanto, em nenhum momento se vê qualquer mobilização no sentido de se coibir os excessos sofridos por estes cidadãos ${ }^{48}$.

Não se pretende fazer um discurso ideológico de classes. Tampouco se entende que deva ser dado a todos o mesmo tratamento dispensado regularmente aos presos "comuns" 49 . Intenta-se apenas demonstrar que o uso de algemas é prática usualmente aceita na grande maioria das prisões, sem questionamento $^{50}$, apesar do voto do Ministro Carlos Britto, no reportado Habeas Corpus, no sentido de estender o benefício a todos os indivíduos, em 
razão da sua condição humana.

Aqui, da mesma forma, como anteriormente exposto, a exposição do indivíduo sendo conduzido à prisão em nada altera, a princípio, em termos de gravame moral, se a condução se dá com ou sem algemas.

Outros fatores podem ser levados em consideração. Por exemplo, a condução feita por policiais ostensivamente armados e identificados com distintivo torna-se mais aparente que aquela levada a cabo por policiais "à paisana". Isso tornaria a medida ilegal, abusiva, desumana ou degradante? A resposta negativa se impõe.

De igual sorte, algemado o preso em local reservado, se a este for assegurada a possibilidade de cobrir os punhos com um casaco ou algo semelhante, seguramente lhe seria menos vexatório. Estas são questões que demonstram ser imperativa a aferição da proporcionalidade no caso concreto. Nos dizeres de Rothenburg, "a proporcionalidade fornece abertura para a consideração das particularidades, ao mesmo tempo em que procura estabelecer parâmetros de racionalidade que conduzam essa aplicação tópica ${ }^{51}$ do Direito"52.

Retornando à incidência da proporcionalidade, cumpre verificar os seus níveis.

Qual o fim pretendido pelo uso de algemas? Se for a exposição indevida do preso, a formação de opinião pública ou a satisfação de interesse pessoal com a divulgação de seu próprio trabalho ou do órgão a que pertence, desde logo, resta afastada a proporcionalidade da medida. Por outro lado, se o objetivo for conduzir a pessoa, assegurando-Ihe a segurança própria e dos que o cercam, evitando a fuga, de pronto resta demonstrada a adequação da constrição.

Quanto à necessidade, surgem maiores dúvidas. De início, pode-se partir da premissa que, não sendo imposta a obrigação de algemar todos os presos, é devido o uso de algemas quando o suposto criminoso for violento comprometendo a integridade física dele ou de outrem -, possa empreender fuga ou, de qualquer forma, possa vir a subjugar seu condutor.

Entretanto, a autoridade não pode saber, de antemão, se estarão presentes tais requisitos, sob pena de se perpetuar um estigma penal. Isso porque, em tese, seriam violentos aqueles que praticaram crimes violentos, ou seja, nos quais houve emprego de violência. Na verdade, trata-se de uma falácia, pois a natureza violenta não pode ser constatada de plano pela autoridade e pessoas violentas podem cometer quaisquer crimes, com ou sem o emprego de violência. Ademais, pessoas usualmente pacíficas podem cometer crimes violentos, v.g., em se tratando de crimes passionais.

Além disso, no que tange à fuga, não é possível antecipar se o sujeito irá se furtar da submissão à persecução criminal. Tendo a liberdade de locomoção como direito inato ao indivíduo, é natural que não se queira vê-la cerceada ${ }^{53}$. 
Nesses moldes, não se afigura simples verificar a necessidade prévia de algemas, mesmo porque as alternativas a seu uso, tais como torções de braço ou estrangulamentos, são muito mais gravosas. Assim, excluindo a hipótese de não utilizá-las, as algemas oferecem menor restrição ao direito e maior eficácia de resultado. Após o uso adequado, a necessidade tampouco pode ser aferida, diante da cessação das razões determinantes. Vale dizer, não é possível, depois de ter sido o preso devidamente conduzido ao local de destino, indagar se ele viria a fugir ${ }^{54}$.

No que tange à proporcionalidade em sentido estrito, exsurgem ainda maiores dificuldades. Sob pena de proteção insuficiente, deve a autoridade zelar pelo equilíbrio entre o respeito à dignidade do acusado e a necessidade de manutenção de uma pretensa ordem pública ${ }^{55}$. Nesse ponto, quando se admite a constrição da liberdade individual de locomoção, em decorrência de determinação judicial, não se afigura proporcional, em nosso modesto entendimento, que se venha a impedir o uso de algemas ${ }^{56}$.

\section{CONCLUSÕES}

Pode-se concluir, com Rodrigo Sánchez Rios ${ }^{57}$, que "há muitas situações que não precisam de mudança na lei. Não dá, por exemplo, para criar regras de uso de algemas".

Não parece razoável a fixação de critérios legais prévios para o uso de algemas, a não ser que se preceitue o uso indiscriminado. Somente no caso concreto, pode 0 agente policial verificar se está presente a proporcionalidade na medida, constatando o perigo de fuga ou o risco à integridade física do preso ou das demais pessoas. Em outras palavras, como salientou o Ministério Público Federal, em parecer acolhido pelo aresto já citado do Superior Tribunal de Justiça, "o uso de algemas há de ser aferido em cada caso concreto, não podendo haver decisum amplo, coibindo-o".

Mostra-se inadmissível, no entanto, a adoção casuística de posicionamento, de molde a conferir dois pesos e duas medidas, estabelecendo distinções indevidas entre sujeitos. Estar-se-ia diante de clara posição discriminatória ${ }^{58}$, seja para autorizar o uso de algemas apenas para os despossuídos, seja para algemar apenas aqueles membros de classe influente, antes intocáveis, no sentido de aplacar a ânsia punitiva da opinião pública.

Por óbvio, nada obsta que as autoridades venham a ser responsabilizadas - civil, administrativa e criminalmente - por conta do abuso de algemas, especialmente pela exposição indevida do preso $^{59}$. Existem fartos instrumentos legais para tanto.

Por fim, uma crítica que se pode fazer ao Projeto de Lei oㅡ 2.753/2000 diz respeito não tanto ao seu conteúdo ou à técnica legislativa empregada, mas sobremaneira ao momento em que será incluído em pauta ${ }^{60}$. Da mesma forma, sem obviamente tecer crítica à notória seriedade de nossos julgadores supremos, a edição da súmula vinculante ํo 11 se deu certamente em 
momento inadequado.

\title{
ON WEARING HANDCUFFS (RESTRICTIONS TO FUNDAMENTAL RIGHTS AND PROPORTIONALITY)
}

\begin{abstract}
This paper briefly analyses fundamental rights and the possibility of its restriction. Then, it approaches the proportionality and the handcuff wear, with its legal and judicial treatment. At last, it analyses wearing handcuffs under the view of proportionality.
\end{abstract} handcuffs.

Keywords: Proportionality. Restrictions to fundamental rights. Wearing

\section{NOTAS}

Analista Judiciário da Justiça Federal da 4ํㅡㄹ Região. Bacharel, Mestre e Doutorando em Direito pela Pontifícia Universidade Católica do Paraná (PUCPR).

* Advogado, Bacharel em Direito pela Pontifícia Universidade Católica do Paraná (PUCPR). Mestre e Doutor em Direito do Estado pela Universidade de São Paulo (USP). Professor da Graduação e Pós-Graduação em Direito da Universidade Federal do Paraná (UFPR) e da Pontifícia Universidade Católica do Paraná (PUCPR).

1 Curiosamente, Satyagraha, em sânscrito, significa algo semelhante a "busca pela verdade" e se trata do princípio de não-violência defendido por Mahatma Gandhi em seu movimento de resistência pacífica.

2 Art. $1^{\circ}$ Caberá prisão temporária:

I - quando imprescindível para as investigações do inquérito policial;

II - quando o indicado não tiver residência fixa ou não fornecer elementos necessários ao esclarecimento de sua identidade;

III - quando houver fundadas razões, de acordo com qualquer prova admitida na legislação penal, de autoria ou participação do indiciado nos seguintes crimes:
a) homicídio doloso (art. 121, caput, e seu $\S 2^{\circ}$ );
b) seqüestro ou cárcere privado (art. 148, caput, e seus $\S \S 1^{\circ}$ e $2^{\circ}$ );
c) roubo (art. 157, caput, e seus $\S \S 1^{\circ}, 2^{\circ}$ e $\left.3^{\circ}\right)$;
d) extorsão (art. 158, caput, e seus $\S \S 1^{\circ}$ e $2^{\circ}$ );
e) extorsão mediante seqüestro (art. 159 , caput, e seus $\S \S 1^{\circ}, 2^{\circ}$ e $3^{\circ}$ );
f) estupro (art. 213, caput, e sua combinação com o art. 223, caput, e parágrafo único);
g) atentado violento ao pudor (art. 214, caput, e sua combinação com o art. 223, caput, e parágrafo único);
h) rapto violento (art. 219, e sua combinação com o art. 223 caput, e parágrafo único);
i) epidemia com resultado de morte (art. $267, \S 1^{\circ}$ );
j) envenenamento de água potável ou substância alimentícia ou medicinal qualificado pela morte (art. 270, caput, combinado com art. 285);
I) quadrilha ou bando (art. 288), todos do Código Penal;
m) genocídio (arts. $1^{\circ}, 2^{\circ}$ e $3^{\circ}$ da Lei $n^{\circ} 2.889$, de $1^{\circ}$ de outubro de 1956 ), em qualquer de sua formas típicas;
n) tráfico de drogas (art. 12 da Lei $n^{\circ} 6.368$, de 21 de outubro de 1976);
o) crimes contra o sistema financeiro (Lei $n^{\circ} 7.492$, de 16 de junho de 1986). 
Esta espécie prisional, classificada como medida subcautelar, salientando ser indispensável o controle judicial e o respeito aos princípios do devido processo legal e da proporcionalidade, imperioso destacar o escólio de Câmara, para quem:

"A prisão temporária, medida marcada por intenso pragmatismo, tem finalidade bastante específica: colocar o suspeito da prática infracional à mercê da autoridade investigante. Nesse sentido tem vigoroso suporte funcional: oportunizar, na fase pré-processual que se produz prova tendo como fonte o próprio investigado. [...] Aí se encontra grave e insuperável problema: podendo haver oposição do acusado, que exercita o direito ao silêncio valendo-se de sua ampla eficácia, a medida instrumental investigatória, atendidos os direitos constitucionais do imputado, tenderia a se revelar inócua. A prisão temporária somente cumpre rigorosamente seus verdadeiros objetivos quando inobservados direitos e garantias constitucionais mínimos colocados à disposição do preso. Essa inobservância, aliás, é corrente na praxis investigativa brasileira, não recebendo oposição das cortes superiores. Tendendo a reforçar a posição do suspeito como mero objeto na fase préprocessual, a prisão temporária é antidemocrática e, talvez, sob essa ótica, inconstitucional" (CÂMARA, Luiz Antonio. Reflexões acerca das medidas cautelares pessoais nos crimes contra o sistema financeiro nacional. In: Coord. GEVAERD, Jair; TONIN, Marta Marília. Direito empresarial \& cidadania: questões contemporâneas. 1 ed. 3 tir. Curitiba: Juruá, 2006, p. 238-239).

3 Juarez Tavares, nas palavras de Ingo Sarlet, adverte que "não se pode negligenciar o papel da mídia na 'construção' de uma política criminal cada vez mais despótica e casuística, o que se torna perceptível a partir da influência dos meios de comunicação sobre a legislação penal, assim como pela tendência - que entre nós poderia ser facilmente demonstrada a partir de alguns exemplos - do legislador atuar de modo casuístico e no mais das vezes movido pela pressão da sociedade em assegurar padrões toleráveis de segurança contra a criminalidade, sem maior preocupação com os resultados concretos e, menos ainda, com a legitimidade constitucional das opções tomadas" (SARLET, Ingo Wolfgang. Constituição, proporcionalidade e direitos fundamentais: o direito penal entre proibição de excesso e de insuficiência. Boletim da Faculdade de Direito, Universidade de Coimbra, vol. LXXXI, 2005, p. 341).

4 No tocante à definição de bens jurídicos penalmente tutelados, oportuno lembrar que 0 renomado penalista alemão Claus Roxin conclui que o ponto de partida correto é que a única restrição previamente imposta ao legislador se encontra nos princípios da Constituição. Serve como critério não somente de criação mas também de interpretação de cada preceito concreto, estando aberta a mudanças sociais e aos progressos do conhecimento científico. (ROXIN, Claus. Derecho penal: parte general. Tomo I. Fundamentos. La estructura de la teoria del delito. Madri: Civitas, 2003, p. 55 e 58.)

5 CANOTILHO, José Joaquim Gomes. Direito constitucional e teoria da constituição. 7 ed. Coimbra: Almedina, 2003, p. 1275.

6 MENDES, Gilmar Ferreira; COELHO, Inocêncio Mártires; BRANCO, Paulo Gustavo Gonet. Curso de direito constitucional. 2. ed. São Paulo; Brasília: Saraiva; IDP, 2008, p. 295, grifo no original.

7 Ibid, loc. cit.

8 CANOTILHO, loc. cit.

9 Ibid, p. 1276. Sugere então os seguintes tipos de restrições: "(1) restrições constitucionais directas ou imediatas, ou seja, restrições directamente estabelecidas pelas próprias normas constitucionais; (2) restrições estabelecidas por lei mediante autorização expressa da constituição (reserva da lei restritiva); (3) restrições não expressamente autorizadas pela constituição, isto é, limites constitucionais não expressos, cuja admissibilidade é postulada pela necessidade de resolução de conflitos de direitos."

10 MENDES et al, op. cit., p. 306-313.

11 São exemplos, no art. 5ำ da Constituição Federal, os incisos VI, VII, XV, XXIV, XXVI a XXIX, XXXIII, XLV, XLVI e LVIII. A lei pode assumir: a) significado instrumental, procedimental ou conformador/criador do direito (art. 5, XXIV e XXXIII, CF); b) caráter substanciador ou definidor do próprio direito fundamental (art. 5ㅇ, XXVI a XXIX, CF); c) aplicação de conceito ou instituto jurídico que reclama densificação (art. 5ำ, XLIII, LXVI e LXVII, CF).

12 Exemplo desta é a interceptação telefônica, somente possível mediante ordem judicial e para investigação criminal ou instrução processual penal. 
13 MENDES et al, op. cit., p. 305, salientam que "a técnica que exige expressa autorização constitucional para intervenção legislativa no âmbito de proteção dos direitos individuais traduz, também, uma preocupação de segurança jurídica, que impede o estabelecimento de restrições arbitrárias ou aleatórias".

MENDES et al, op. cit., p. 298.

MENDES et al, op. cit., p. 299.

MENDES et al, op. cit., p. 300-301.

MENDES et al, op. cit., p. 314.

18 Segundo K. H. Wernicke (apud MENDES et al, op. cit., p. 314 e ss.), são "limites dos limites".

19 Apud BONAVIDES, Paulo. Curso de direito constitucional. 5 ed. São Paulo: Malheiros, 1994, p. 356.

BONAVIDES, op. cit., p. 357.

Ibid, loc. cit.

Walter Claudius Rothenburg defende que a proporcionalidade é um "critério", não um princípio, apesar do título de seu artigo. Justifica sua opção por quatro razões: a) de conteúdo; b) de objeto; c) de pertinência; e d) de incidência. Primeiro, a proporcionalidade se refere a como as normas devem ser aplicadas, destinando-se aos intérpretes do Direito e não aos seus destinatários. Segundo, ao invés de se referir a comportamentos em geral, refere-se às normas jurídicas e como se relacionam na sua aplicação. Terceiro, não funciona como comando de conduta, mas como regra de interpretação/aplicação do Direito. Quarto, a proporcionalidade se aplica de forma constante, sem variações. (ROTHENBURG Walter Claudius. Princípio da proporcionalidade. In: LOPES, Maria Elizabeth de Castro; OLIVEIRA NETO, Olavo de. (coord.) Princípios processuais civis na Constituição. Rio de Janeiro: Elsevier, 2008, p. 292-294.)

Por sua vez, SARLET, op. cit, p. 360, aborda a "discussão em torno da qualificação jurídico-normativa da proporcionalidade, já que se discute a sua condição de princípio ou de regra (tomando-se aqui ambas as noções tal qual formuladas teoricamente por Robert Alexy e seus seguidores), isto sem falar nas considerações mais recentes questionando a condição propriamente principiológica da proporcionalidade (especialmente em se partindo dos referências [sic.] apresentados por Alexy) que, segundo esta doutrina, notadamente quando se cuidar do controle de constitucionalidade (proporcionalidade) de atos estatais, assume feições de postulado normativo-aplicativo, razão pela qual se faz referência a um dever de proporcionalidade".

23 CANOTILHO, op. cit., p. 266-273.

Segundo o autor, a Constituição Portuguesa trata do princípio da proibição do excesso especialmente nos seguintes artigos:

Art. 18. / 2. A lei só pode restringir os direitos, liberdades e garantias nos casos expressamente previstos na Constituição, devendo as restrições limitar-se ao necessário para salvaguardar outros direitos ou interesses constitucionalmente protegidos.

Art. 19. / 4. A opção pelo estado de sítio ou pelo estado de emergência, bem como as respectivas declaração e execução, devem respeitar o princípio da proporcionalidade e limitar-se, nomeadamente quanto às suas extensão e duração e aos meios utilizados, ao estritamente necessário ao pronto restabelecimento da normalidade constitucional.

Art. 266. / 2. Os órgãos e agentes administrativos estão subordinados à Constituição e à lei e devem actuar, no exercício das suas funções, com respeito pelos princípios da igualdade, da proporcionalidade, da justiça, da imparcialidade e da boa fé.

24 Ibid, p. 92, alerta que "qualquer que seja o conceito e a justificação do Estado - e existem vários conceitos e várias justificações - o Estado só se concebe hoje como Estado Constitucional". O autor destaca que o Estado Constitucional tem duas qualidades que 0 definem: Estado democrático e Estado de direito.

25 Ibid, p. 266.

26 Na Europa, CANOTILHO, op. cit., p. 268, grifos no original, realça que "o princípio da proporcionalidade ou da proibição do excesso é, hoje, assumido como um princípio de controlo exercido pelos tribunais sobre a adequação dos meios administrativos (sobretudo coactivos) à prossecução do escopo e ao balanceamento concreto dos direitos ou interesses em conflito.

27 ROTHENBURG, op. cit., p. 300-309, aborda outras divisões. A divisão bipartida desconsidera a proporcionalidade em sentido estrito. De igual sorte, outra divisão, quadripartida, posiciona, ao lado da adequação e da necessidade, a constitucionalidade do 
fim e a constitucionalidade do meio. O fim deve ser constitucional, à semelhança da possibilidade jurídica do pedido como condição da ação. Além disso, os meios, conquanto aptos a atingir a finalidade, não podem ser contrários ao ordenamento jurídico, v.g., não se pode fazer uso de provas ilícitas para combater a impunidade, diante da vedação do art. 5ํㅡ, LVI, da Constituição Federal.

28 "Dada a natural relatividade do princípio, a doutrina tenta acrescentar outros elementos conducentes a uma maior operacionalidade prática: a) a exigibilidade material, pois o meio deve ser o mais <<poupado>> possível quanto à limitação dos direitos fundamentais; $b$ ) a exigibilidade espacial aponta para a necessidade de limitar o âmbito da intervenção; c) a exigibilidade temporal pressupõe a rigorosa delimitação no tempo da medida coactiva do poder público; d) a exigibilidade pessoal significa que a medida se deve limitar à pessoa ou pessoas cujos interesses devem ser sacrificados" (CANOTILHO, op. cit., p. 270, grifos no original).

ROTHENBURG, op. cit., p. 297.

30 BONAVIDES, op. cit., p. 360-361.

${ }^{31}$ CANOTILHO, op. cit., p. 270, grifos no original.

32 Assim, segundo MENDES et al, op. cit., p. 332, "um juízo definitivo sobre a proporcionalidade da medida há de resultar da rigorosa ponderação e do possível equilíbrio entre o significado da intervenção para o atingido e os objetivos perseguidos pelo legislador (proporcionalidade em sentido estrito)".

33 Não necessariamente jurisprudência, porque não configuram decisões reiteradas dos Tribunais.

34 O substitutivo da Comissão de Constituição e Justiça dará a seguinte redação ao dispositivo:

"Art. 199. É permitido o emprego de algemas quando os destinatários das medidas coercitivas:

I - resistirem ou desobedecerem à ordem de prisão;

II - tentarem fugir ou derem indícios de que pretendem fugir;

III - coloquem em risco a própria integridade ou a de outrem;

IV - superarem em número ou em força o efetivo de agentes estatais destinados ao cumprimento da medida;

V - venham a ser deslocados de um local para outro, em função de comparecimento compulsório em ato judicial.

$\S 1^{\circ}$ Consideram-se algemas, para os efeitos desta Lei, qualquer meio material destinado à contenção de pessoas.

$\S 2^{\circ} \mathrm{A}$ autoridade imediatamente responsável pela ação policial deverá decidir sobre 0 emprego de algemas, obrigando-se a preservar o preso da execração pública, bem como de quaisquer agressões físicas ou morais."

35 No Estado Constitucional, entendido como forma de manifestação do poder político regido por um estatuto fundamental, cabe ao Judiciário "arbitrar os inevitáveis conflitos entre os fatores reais de poder" (MENDES et al., op. cit., p. 133), em grande parte provocado pela oposição que visa estorvar a ação governamental, que, por sua vez, intenta implementar os programas prometidos em campanha.

Conforme Sebastián Soler, os limites do ordenamento jurídico são, de um lado, a Constituição e a coisa julgada, de outro extremo. Tal se dá por necessidade não somente lógica, porque inconcebível um sistema infinito, mas também axiológica, pois a convivência social depende de "um mínimo de segurança e de previsibilidade quanto ao desfecho dos conflitos humanos" (apud MENDES et al, p. 134). Entre os dois pólos, encontram-se os órgãos e autoridades legitimados à Jurisdição (dizer o direito).

Operação destinada a investigar "venda de sentenças" na Justiça Federal em São Paulo.

"HABEAS CORPUS. PENAL. PROCESSUAL PENAL.

Os pedidos referentes a: apuração de responsabilidade por haver violação de segredo de justiça, proibição de veiculação de imagens do paciente e fixação de mensagem, vedando filmagens, no Tribunal, não são compatíveis com o objeto da ação constitucional eleita, que se restringe à liberdade de locomoção.

O uso de algemas pelos agentes policiais não pode ser coibido, de forma genérica, porque algemas são utilizadas, para atender a diversos fins, inclusive proteção do próprio paciente, quando, em determinado momento, pode pretender autodestruição." Ordem denegada.

(HC 35540/SP, Rel. Ministro José Arnaldo da Fonseca, 5a Turma, julg. 05.08.2004, DJ 06.09.2004 p. 285) 
Merece destaque a concessão de liminar em Habeas Corpus pelo Presidente do STJ, em 16/07/2008, requerido por ex-banqueiro extraditado para o Brasil, oportunidade em que foi divulgada notícia pela assessoria de imprensa na qual restaram expostas as razões adotadas, com o seguinte teor: "Para o ministro Humberto Gomes de Barros, o uso de algemas é legítimo dentro da finalidade de garantir o cumprimento de diligência policial ou de preservar a segurança do preso, de terceiros e das autoridades policiais. No entanto, entende, não pode ocorrer 'como instrumento de constrangimento abusivo à integridade física ou moral do preso'. O ministro destaca, ainda, que [opta-se por não divulgar o nome do paciente] é idoso, não podendo oferecer resistência aos policiais federais que integram a comitiva responsável pela escolta".

38 ADMINISTRATIVO. RESPONSABILIDADE CIVIL DO ESTADO. USO DE ALGEMAS. AFERIÇÃO DE RAZOABILIDADE.

1. O uso de algemas pela força policial deve ficar adstrito a garantir a efetividade da operação e a segurança de todos os envolvidos.

2. Demonstra-se razoável o uso de algemas, mesmo inexistindo resistência à prisão, quando existir tumulto que o justifique.

Afasta-se a condenação da União por danos morais.

3. Recurso especial provido.

(REsp 571.924/PR, Rel. Ministro Castro Meira, 2ª Turma, julg. 24.10.2006, DJ 10.11.2006, p. 255)

39 Na oportunidade, assim restou ementado:

HABEAS CORPUS. PENAL. USO DE ALGEMAS NO MOMENTO DA PRISÃO. AUSÊNCIA DE JUSTIFICATIVA EM FACE DA CONDUTA PASSIVA DO PACIENTE. CONSTRANGIMENTO ILEGAL. PRECEDENTES. 1. O uso legítimo de algemas não é arbitrário, sendo de natureza excepcional, a ser adotado nos casos e com as finalidades de impedir, prevenir ou dificultar a fuga ou reação indevida do preso, desde que haja fundada suspeita ou justificado receio de que tanto venha a ocorrer, e para evitar agressão do preso contra os próprios policiais, contra terceiros ou contra si mesmo. O emprego dessa medida tem como balizamento jurídico necessário os princípios da proporcionalidade e da razoabilidade. Precedentes. 2. Habeas corpus concedido. (HC 89429/RO, $1^{\text {a }}$ Turma, Rel. Min. Cármen Lúcia, julg. 22/08/2006, DJ 02/02/2007, p. 920)

40 Desencadeada pela Polícia Federal em 04/08/2006, com o fito de investigar crimes supostamente praticados por organização criminosa que teria atuado na Assembléia Legislativa do Estado de Rondônia.

41 Não se pode olvidar que os princípios da constituição, normas com que trabalham as cortes constitucionais, "apresentam-se em fórmulas lapidares, numa linguagem tão aberta, indeterminada e plurissignificativa, que 0 ato de concretizá-las a rigor não conhece limites" (MENDES et al, p. 139). Trata-se de algo semelhante a atos de interpretação, mas mais grave, pois a interpretação constitucional se espraia por todo o ordenamento.

Por isso é que se critica a atuação legiferante (ou de míni-constituintes) das cortes constitucionais, embora sem legitimidade política para tanto, em razão das regras hermenêuticas de que se utilizam, as quais, por sua indefinição, permitem-Ihes manipular a Constituição.

No entanto, os autores ainda ressaltam que a própria organização desses tribunais extraordinários demonstra que os instituidores da jurisdição constitucional deliberadamente a conceberam como instância de avaliação jurídico-política da atividade legislativa, sem que essa opção implicasse quer a politização da justiça, quer a judicialização da política.

Muito ao contrário, salientam, o que se verifica é que mesmo gozando de ampla liberdade para escolher os seus representantes nas cortes constitucionais, jamais algum segmento político indicou pessoas desequilibradas ou desqualificadas para compor essa magistratura suprema. Afinal de contas, a todos parece óbvio que sem o respeito da própria sociedade, que as instituiu e mantém, essas cortes não teriam condições de arbitrar-Ihe os grandes conflitos políticos e ver acatadas as suas decisões.

Essa reflexão se afigura por demais pertinente atualmente - e isto se constata sem que tal configure crítica ou defesa -, quando variados segmentos representativos da sociedade criticaram, ainda que açodadamente, o posicionamento adotado por um dos autores, na qualidade de Presidente do Supremo Tribunal Federal.

42 Afinal, qual o termo correto: proporcionalidade ou razoabilidade? "Tenho a impressão de que se trata, com freqüência e talvez sem cuidado, de mera troca de palavras para traduzir a mesma idéia. As distinções são superficiais e talvez residam na origem e respectivo 
contexto cultural (enquanto a proporcionalidade teria origem alemã, a razoabilidade teria origem inglesa); entre gênero e espécie (enquanto a proporcionalidade seria mais ampla, a razoabilidade corresponderia apenas a um dos aspectos daquela: a adequação, ou quem sabe, até a proporcionalidade em sentido estrito); na relação estabelecida (enquanto a proporcionalidade 'exige a relação de causalidade entre meio e fim', a razoabilidade 'exige a relação das normas com suas condições externas de aplicação', sem que haja 'entrecruzamento horizontal de princípios' (Humberto Ávila)" (ROTHENBURG, op. cit., p. 314 , grifos no original).

Para breve e elucidativo esclarecimento acerca das "variantes terminológicas", confira-se: BARROS, Suzana de Toledo. 0 princípio da proporcionalidade e o controle de constitucionalidade das leis restritivas de direitos fundamentais. Brasília: Brasília Jurídica, 2000, p. 69-74.

${ }^{43} \mathrm{O}$ acórdão ainda não foi publicação, mas se encontra no sítio do STF. Disponível em: http://www.stf.jus.br/arquivo/cms/noticiaNoticiaStf/anexo/hc91952.pdf . Acesso em: 15 ago. 2008.

44 RHC 56465/SP, 2 ${ }^{a}$ Turma, Rel. Min. Cordeiro Guerra, julg. 05/09/1978, DJ 06/10/1978 e HC 71195/SP, 2 ${ }^{\text {a }}$ Turma, Rel. Min. Francisco Rezek, julg. 25/10/1994, DJ 04/08/1995, p. 22442. Por fugir aos limites do presente trabalho, não se pretende discutir se a decisão da edição da súmula vinculante cumpre ou não os requisitos necessários previstos pelo art. 103-A, da Constituição Federal. Em uma análise superficial, pode-se criticar o açodamento em se sumular a questão, diante de decisões não propriamente reiteradas. Pode-se ainda salientar não ser possível vislumbrar especificamente a norma que exige interpretação extensiva a todas as hipóteses de uso de algemas. Tampouco se identifica, nos termos do preceito constitucional, a existência de "controvérsia atual entre órgãos judiciários ou entre esses e a administração pública que acarrete grave insegurança jurídica e relevante multiplicação de processos sobre questão idêntica".

45 Por ocasião dos debates, o Procurador-Geral da República, Dr. Antônio Fernando Barros e Silva de Souza, demonstrou dúvidas com relação à generalidade da medida e consternação com a possível anulação de atos por conta do uso de algemas. Salientou que:

"A preocupação do Ministério Público, exatamente porque tem atribuições de controle externo, é porque, nessa segunda situação, a observância dessa regra gera maior tensão. Porque a própria avaliação de quem fará a prisão pode se frustrar diante de uma compreensão equivocada da conduta da própria pessoa ou de quem estiver próximo. É uma preocupação com a aplicação do comando dessa súmula em face de situações concretas. Da mesma maneira que se preserva, com razão, a dignidade da pessoa humana - e o Ministério Público está ao lado dessa tese -, também temos de ter a consciência de que não podemos partir da presunção contrária de que o agente do Estado - o policial -, quando cumpre com os seus deveres, também estaria, presumidamente, violando a regra." Disponível

http://www.stf.jus.br/arquivo/cms/jurisprudenciaSumulaVinculante/anexo/DJE 11.11.2008.p df. Acesso em: 13 nov. 2008.

46 Trata-se de restrição estabelecida por lei mediante autorização expressa da constituição (reserva da lei restritiva). Como exemplo, tem-se que configura evasão de divisas a conduta de promover, sem autorização legal, a saída de moeda ou divisa para o exterior, consoante tipifica o art. 22, parágrafo único, $1^{\text {a }}$ parte, da Lei oํ 7.492/86.

47 Lei $n^{\circ}$ 4.898/65. Art. 4ํㅡㄴ Constitui também abuso de autoridade: [...]

b) submeter pessoa sob sua guarda ou custódia a vexame ou a constrangimento não autorizado em lei;

48 Disponível em:

http://www.stf.jus.br/arquivo/cms/jurisprudenciaSumulaVinculante/anexo/DJE_11.11.2008.p df. Acesso em: 13 nov. 2008.

49 Neste sentido é a observação de José Eduardo Faria, "para quem os segmentos excluídos da população, vítimas das mais diversas formas de violência física, simbólica ou moral resultantes da opressão sócio-econômica - acabam não aparecendo como portadores de direitos subjetivos públicos, não podendo, portanto, nem mesmo ser considerados como ' sujeitos de direito', já que excluídos, em maior ou menor grau, do âmbito de proteção dos direitos e garantias fundamentais" (SARLET, op. cit., p. 333).

50 Foi noticiado que, em 04/02/2008, em meio ao carnaval, um juiz federal foi abordado, sem aparente motivo, por policiais civis do CORE - Coordenadoria de Recursos Especiais do 
Rio de Janeiro. Mesmo após sua identificação, o magistrado foi algemado e conduzido na viatura à delegacia, onde a imprensa lhe aguardava. À época, o fato foi objeto de desagravo por parte dos órgãos de classe, sendo que uma manifestação pública destacou "que este ato intolerável e inaceitável cometido contra um juiz federal sirva de alerta e mobilizador contra as arbitrariedades de qualquer natureza, em especial agressões físicas contra cidadãos. Jamais se logrará êxito na luta contra o crime e a violência com base na arbitrariedade, na conduta abusiva de agentes policiais, e fora dos parâmetros democráticos fixados na Constituição". Disponível em: http://www.ajufe.org.br/003/0030eheheheh1009.asp?ttCD_CHAVE=51055 . Acesso em: 18 jul. 2008.

51 Verifica-se que "o Estado busca efetivar os seus deveres de proteção encarando os grupos sociais mais fracos como fatores de risco, priorizando a política criminal e negligenciando as suas obrigações no âmbito da segurança social. Da mesma forma - e talvez por esta mesma razão - o garantismo penal na sua dimensão negativa acaba não raras vezes privilegiando a elite econômica ou as classes mais influentes da sociedade, deixando de criminalizar (ou mesmo descriminalizando) delitos de cunho econômico e tributário" (SARLET, op. cit., p. 342).

52 Sobre o método tópico de interpretação constitucional, pode-se compulsar BONAVIDES, op. cit., p. 446-454.

53 ROTHENBURG, op. cit., p. 313.

54 Por tal razão é que não se pune criminalmente a fuga do preso, senão mediante violência contra a pessoa (art. 351, do Código Penal).

Em setembro de 2007, foi noticiado pelo site Consultor Jurídico que o Ministro Marco Aurélio teria afirmado que "enquanto a culpa não está formada, mediante um título do qual não caiba mais recurso, o acusado tem o direito - que eu aponto como natural - que é o direito de fugir para evitar uma glosa que seria precipitada". Ainda teria argumentado que, para manter uma prisão, "é preciso um dado concreto quanto à periculosidade, quanto à tentativa de influenciar para obstaculizar a aplicação da lei penal, mas sempre com um dado concreto". Disponível em: http://www.conjur.com.br/static/text/59566,1 . Acesso em: 22 mai. 2008.

55 Tem-se dois exemplos dessa impossibilidade de verificação. O caso (folclórico) de expolítico paranaense, acusado de gestão fraudulenta de consórcio, que, para evitar o cumprimento de mandado de prisão, conforme noticiou a imprensa, escondeu-se em uma casa de boneca e subiu em uma árvore, onde foi preso. O ex-banqueiro já citado, recentemente extraditado, quando beneficiado por Habeas Corpus, evadiu-se para a Europa.

56 SARLET, op. cit., p. 350, salienta que "o exercício de direitos individuais está condicionado, de certa forma, ao seu reconhecimento pela comunidade na qual se encontra inserido e da qual não pode ser dissociado, podendo falar-se, neste contexto, de uma responsabilidade comunitária dos indivíduos. É neste sentido que se justifica a afirmação de que a perspectiva objetiva dos direitos fundamentais não só legitima restrições aos direitos subjetivos individuais com base no interesse comunitário prevalente, mas também e de certa forma, que contribui para a limitação do conteúdo e do alcance dos direitos fundamentais, ainda que deva sempre ficar preservado o núcleo essencial destes e desde que estejamos atentos ao fato de que com isto não se está a legitimar uma funcionalização (e subordinação apriorística) dos direitos fundamentais em prol dos interesses da coletividade".

57 Reitere-se que a exposição do preso não é objeto de detida análise no presente estudo. Mas, adiantado nosso posicionamento, entende-se que a divulgação de prisões pela imprensa é extremamente danosa, não somente aos sujeitos à medida constritiva, mas ao próprio sucesso da operação, quando se depende de sigilo para outras diligências. $\mathrm{Na}$ própria Operação Satiagraha, o banqueiro investidor impetrou Habeas Corpus preventivo, alegando fundado receio de ser preso, baseado em notas difundidas pela mídia, apuradas por vazamento de informações. Nesse tipo de operação, por vezes há o cumprimento concomitante de ordens em diferentes cidades. Assim, v.g., se o jornalista noticiar uma prisão em São Paulo, isso pode vir a obstar a prisão de outro membro da organização criminosa em Roraima.

58 Advogado criminalista e professor deste PPGD, em entrevista ao jornal Gazeta do Povo, narrou fato em que foi vítima de evidentemente desproporcional uso de algemas, 
determinado por magistrado, em audiência na qual ele insistiu em formular pergunta a testemunha.

59 Conforme salientado, a questão comportaria estudo específico acerca do conflito entre a liberdade de informação dos meios de comunicação e a intimidade, a honra ou outros direitos do preso, não eliminados com a privação da liberdade.

60 Em outra oportunidade, mas com pertinência à presente situação, já se ressaltou que "a edição de novas leis penais não se deve prestar a fins eleitoreiros, visando objetivos imediatos ou ocultos. Leis divorciadas da realidade, que não demonstram claramente 0 bem jurídico tutelado, que padecem de inconstitucionalidade e, principalmente, que não são precedidas pela análise dos meios administrativos e financeiros necessários à sua efetivação ou dos reflexos sociais da sua edição são leis editadas para não serem cumpridas. Dentre estas, as piores leis são aquelas precedidas por grande divulgação na mídia acerca de sua importância e miraculosos efeitos, relegando posteriormente aos magistrados a impopular função de decretar a sua ineficácia ou limitar gravemente os seus efeitos." (SILVA, Daniel Addor; SÁNCHEZ RIOS, Rodrigo. Adoção da insignificância para um novo significado ao direito penal. In: GARCIA, Ruben Teixeira. (Org.). Direito em mapa multidisciplinar e cultural. Porto Alegre: Verbo Jurídico, 2008, p. 322.)

\section{REFERÊNCIAS}

BARROS, Suzana de Toledo. O princípio da proporcionalidade e o controle de constitucionalidade das leis restritivas de direitos fundamentais. Brasília: Brasília Jurídica, 2000.

BONAVIDES, Paulo. Curso de direito constitucional. 5. ed. São Paulo: Malheiros, 1994.

CÂMARA, Luiz Antonio. Reflexões acerca das medidas cautelares pessoais nos crimes contra o sistema financeiro nacional. In: Coord. GEVAERD, Jair; TONIN, Marta Marília. Direito empresarial \& cidadania: questões contemporâneas. 1. ed. 3 tir. Curitiba: Juruá, 2006, p. 238-239.

CANOTILHO, José Joaquim Gomes. Direito constitucional e teoria da constituição. 7. ed. Coimbra: Almedina, 2003.

GONÇALVES, André. Testemunhos. Gazeta do Povo, Curitiba, 27 jul. 2008. Vida Pública, p. 2.

MENDES, Gilmar Ferreira; COELHO, Inocêncio Mártires; BRANCO, Paulo Gustavo Gonet. Curso de direito constitucional. 2. ed. São Paulo; Brasília: Saraiva; IDP, 2008.

NICZ, Alvacir Alfredo. Iniciativa privada versus iniciativa estatal na Constituição. Brasília, Revista de Informação Legislativa, a. 41, n. 163, p. 261-279, jul./set. 2004.

ROTHENBURG, Walter Claudius. Princípio da proporcionalidade. In: LOPES, Maria Elizabeth de Castro; OLIVEIRA NETO, Olavo de. (coord.) Princípios processuais civis na Constituição. Rio de Janeiro: Elsevier, 2008.

ROXIN, Claus. Derecho penal: parte general. Tomo I. Fundamentos. La estructura de la teoria del delito. Madri: Civitas, 2003.

SARLET, Ingo Wolfgang. Constituição, proporcionalidade e direitos fundamentais: o direito penal entre proibição de excesso e de insuficiência. Boletim da Faculdade de Direito, Universidade de Coimbra, vol. LXXXI, p. 325386, 2005. 
SILVA, Daniel Addor; SÁNCHEZ RIOS, Rodrigo. Adoção da insignificância para um novo significado ao direito penal. In: GARCIA, Ruben Teixeira. (Org.). Direito em mapa multidisciplinar e cultural. Porto Alegre: Verbo Jurídico, 2008, p. 305-324.

Recebido para publicação 14/11/2008

Aceito para publicação 15/11/2008 